\title{
MicroRNA29-a as Diabetic Nephropathy Biomarker in Diabetic Patients (Type 2)
}

\author{
MOHAMED Y. NASR, M.D.*; SALWA E. MOHAMED, M.D.*; AHMED M. HASSANAIN, M.D.**; \\ RANDA A. GHANOUM, M.D.** and SABAH F. EL-ABED, M.D.* \\ The Department of Molecular Biology, Genetic Engineering \& Biotechnology Institut, Sadaat City University* and \\ Laboratory Department, National Heart Institute, General Organization of Hospitals\& Teaching Institutes, Ministry of Healthy
}

\begin{abstract}
Background: Diabetic nephropathy (DN) is one of the main causes of renal failure. Recent research demonstrated that the serial microbes (miRNA) could be used as a marker to detect pathogenic disease; the DN-related miRNAs could not be studied.

Aim of Study: In this study the aim was to investigate the predictive value of miRNA29-a in diabetes mellitus type 2 (T2DM) patients in relation to nephropathy risk onset prediction.

Subjects and Methods: In the present study a total of (120) persons were divided into three groups as Group (I): $(\mathrm{N}=20)$ control group, Group (II): $(\mathrm{N}=50)$ T2DM patients without renal symptoms Group (III): $(\mathrm{N}=50)$ T2DM patients with renal insufficiency, RT-PCR method was used to determine the relative quantitative of miRNA29-a.

Results: Increased levels of $\mathrm{HbA1c}$, FBS, urea, creatinine and Albumin/creatinine ratio (ACR) were observed in subjects under study.An increased levels of miRNA 29-a in group III, DN $(51.97,61.78)$ and group II, DM $(7.06 \pm 6.83)$ when compared with group I, control subjects $(0.8,0.2)$. The result of the present study implied that miRNA $29-$ a could be served as an early indicator of DM-mediated renal pathogenesis.
\end{abstract}

Key Words: Diabetes mellitus type 2 -Diabetic nephropathy - Circulating microRNA - Biomarker.

\section{Introduction}

DIABETES mellitus (DM) is a group of metabolic problems propertied by chronic high blood sugar condition caused by insufficiency of insulin secretion, insulin activity or both [1]. Diabetes mellitus (T2DM) is a dominant type of diabetes and represents at least $90 \%$ of all cases of diabetes [2]. The incidence of T2DM has increased exponentially, especially in developed countries [3,4]. Macro and microvascular complications of diabetes are mainly

Correspondence to: Dr. Ahmed M. Hassanain,

E-mail: a.hassanain@yahoo.com. due to prolongation of exposure to hyperglycaemia [5]

Diabetes enhances the individual's risk of developing cardiovascular Disease (CVD) $[6,7]$ Diabetes mellitus is also a strong independent prediction of risk stroke and cerebrovascular disease, such as coronary artery disease [8]. Diabetic retinopathy can be the most common microvascular complication of diabetes [9]. Diabetes neuropathy also accompanies diabetes mellitus complications which leads to significant diseases and mortality even in patients with diabetes [10]. Diabetic nephropathy (DN) is a renal complication of diabetes mellitus. The pathogenesis of DN includes the deregulation of various biological functions [11] A study has estimated about $40 \%$ of T2DM patients develop DN [12]

Among clinical characteristics of DN They include persistent albuminuria and a gradual decrease in glomerular filtration rate (GFR), although low level of albuminuria (30-300mg/day) could be detected in patients with early and reversible $\mathrm{DN}$, evident proteinuria $(>300 \mathrm{mg} / \mathrm{day})$ represents irreversible level of DN [13]. Analysis of microbiobacteria is an ideal method for detecting DN in early stages, but it has around by problems such as micro albuminuria can develop with advanced medical conditions [14]

Indeed, a new and more sensitive biomarker for early detection of renal failure with relative minimal invasive sampling and simple experimentation procedure is required $[\mathbf{1 5 , 1 6 ]}$. Many studies have suggested the new family of indigenous, small (about 19-22 nucleotides), single stranded noncode RNA molecules known as microRNAs (miRNAs) as observers development. These molecules 
have been shown to play important roles in modulating gene expression $[\mathbf{1 7 , 1 8}]$. It is estimated that about $60 \%$ of human protein-gene coding can be controlled by miRNAs [19]. Several studies have estimated that miRNAs have vital regulators of gene expression, including cancer, hepatitis, and diabetes, [20,21]. MiRNA29 is involved in pathogenicity DN targets Spry1 in db/db mice or collagen in diabetes mellitus caused by STZ [22,23]

\section{Subjects and Methods}

\section{Subjects:}

The current study was conducted on a total of (120) persons, the study was previously approved by The Ethical Committee of Molecular Biology Dept., Genetic Engineering \& Biotechnology Research Institute (GEBRI), university of Sadaat City. Written informed consent was obtained from all patients. The patient's samples (serum) were collected under the approval of National Kidney Institute, Matarya, Cairo, Egypt from May 2018 July 2018. All patient samples were recruited from the emergency department. Individual were divided into three groups as the following: Group (I): Included (20) healthy volunteers, control group, Group (II): Included (50) consecutive Egyptian T2DM without renal symptoms were constituted as predictive group for renal impairment developing symptoms. Group (III): Included (50) Egyptian T2DM patients with renal insufficiency were suggested of renal impairment.

\section{Blood sampling and serum preparation:}

A $7 \mathrm{ml}$ Peripheral venous blood was collected and distributed into a $2 \mathrm{ml}$ was collected into EDTA tube, stored as a whole blood at $4^{\circ} \mathrm{C}$ until used to determine HBA1c level. A $5 \mathrm{ml}$ blood was collected into uncoated tube; serum was collected and stored in aliquots at $-80^{\circ} \mathrm{C}$ until used. Serum samples were divided into two parts. (i) Serum was used to determine (F.B.S, urea \& creatinine). (ii) Serum was used to isolate total RNA containing miRNA 29-a.

\section{Urine samples collection \& preparation:}

Random urine samples were collected, centrifuged; supernatant was collected, and stored at $20^{\circ} \mathrm{C}$ until used to determine albumin/creatinine ratio level.

\section{Methods:}

\section{Biochemical parameters:}

Estimation of fasting blood sugar level:

Serum glucose was assayed by using Diamond diagnostics Kit (Diamond Diagnostics Company,
Cairo, Egypt) according to [24].

$$
\text { Estimation Glycosylated Hemoglobin (HBAlc) }
$$
level:

HBA1c was determined by using BIOMED diagnostics Kit (EGY-CHEM Diagnostics Company, Cairo, Egypt) according to [25]

\section{Estimation of serum urea level:}

Serum urea was determined by using Diamond diagnostics Kit (Diamond Diagnostics Company, Cairo, Egypt) according to [26].

\section{Estimation serum creatinine level:}

Serum creatinine level was determined by using Diamond diagnostics Kit (Diamond Diagnostics Company, Cairo, Egypt). Jaffe, colorimetric Kinetic method according to [26]

\section{Estimation of albumin/creatinine ratio level:}

Albumin/Creatinine Ratio level in urine was determined by using BioVision (ACR) kit, (Sunrise TECAN, Austria) according to the manufacturer's instructions.

\section{Real-time reverse transcriptase ( $R T)-P C R$ :}

In the present study the real-time reverse transcription (RT)-PCR method was used to detect and determine the relative quantitative (RQ) miR29a in subjects serum under study. Total RNA containing small RNA was isolated from $250 \propto 1$ of serum using miRNeasy Mini Kit (QIAGEN). Total RNA was converted to cDNA by using the miScript ${ }^{\circledR} 11$ RT. Kit (QIAGEN). Real-Time PCR was performed using ViiATM 7 system (Applied Biosystems) by using 2x Quanti Tect SYBR Green PCR Master Mix and RT-PCR reagents Kit to amplify the miRNA29-a cDNA. Briefly, Atypical PCR reaction mix was Prepared as a $25 \propto 1$ per well reaction volume as following 2x Quanti Tect SYBR green PCR master mix $12.5 \propto 1.10 x$ miScript universal primer $2.5 \propto 1.10 \mathrm{x}$ miScript primer assay $2.5 \propto 1$. RNase-freewater $5 \propto 1$.TemplatecDNA $2.5 \propto 1$. The amplification of the samples were carried out with the following cycling $15 \mathrm{~min}$ heat start at $95^{\circ} \mathrm{C}$, followed by 40 cycles of denaturation at $94^{\circ} \mathrm{C}$ for 15 second, annealing/fluorescence detection at $60^{\circ} \mathrm{C}$ for $1 \mathrm{~min}$. The internal control gene, noncoding small RNA Hs-SNORD68-11, was used according to the applied biosystems application note. The Relative quantitative (RQ) of miR29-a in the studied subjects were calculated using noncoding small RNA Hs-SNORD68 as an internal control. The point at which the amplification plot crossed the threshold was defined as threshold cycle CT, ACT was determined by subtraction CT that of Hs-SNORD68 (calibrator) from CT of target 
miR29-a, $\Delta \Delta \mathrm{CT}$ was calculated by subtraction $(\Delta \mathrm{CT})$ of control subjects from $(\Delta \mathrm{CT})$ of target miR29-a, finally, Relative quantitative (RQ) of $\operatorname{miR} 29-\mathrm{a}=2\left({ }^{-} \Delta \Delta \mathrm{CT}\right)$.

\section{Statistical analysis:}

Comparisons among different groups were performed by one way analysis of variance (ANOVA). It is a parametric statistical analysis that compares between-and within-groups variance to measure differences between two or more groups. All statistical analysis were performed by using statistical software packages namely (SPSS, version 17) (SPSS Inc.Chicago, USA). $p$-values of less than 0.05 were considered to indicate statistical significance. All these results were expressed as mean \pm SD.

\section{Results}

Diabetes and kidney functions markers:

The miRNA29-a was assayed and correlated to HBA1 c, fasting blood sugar and renal functions including serum urea $\&$ creatinine levels and albu$\mathrm{min} /$ creatinine ratio. The present study showed a significantly increased levels of miRNA29a (RQ) $(p$-value $<0.05)$ in subjects that had a high level of HBA1c \& FBS, also an elevated levels of miRNA29-a were observed in diabetic subjects that had a high levels of urea, creatinine \& ACR. We reported that serum miR-29-a was significantly elevated in T2DM patients with aggressive $\mathrm{DN}$, based on ACR, urea and creatinine.

Data represented in Table (1) show the levels of diabetes markers i.e. (FBS, HBA1c) and kidney function markers i.e. (urea, Creatinine $\&$ alb/creat ratio) in the serum of control and other studied groups. Marked significant elevation $(p<0.05)$ in the activities of these markers were observed in group II, DM \& group III, DN when compared with group I, control subjects.

Table (1): Clinical information of subjects recruited in the present study.

\begin{tabular}{llll}
\hline $\begin{array}{l}\text { Analytical } \\
\text { parameter }\end{array}$ & \multicolumn{1}{c}{$\begin{array}{c}\text { Group I } \\
\mathrm{N}=20\end{array}$} & $\begin{array}{c}\text { Group II } \\
\mathrm{N}=50\end{array}$ & \multicolumn{1}{c}{$\begin{array}{c}\text { Group III } \\
\mathrm{N}=50\end{array}$} \\
\hline FBS (mg/dl) & $89.10 \pm 11.58$ & $187.02 \pm 82.44$ & $216.64 \pm 75.10$ \\
HBA1c (\%) & $5.41 \pm 0.41$ & $8.33 \pm 1.86$ & $8.5 \pm 1.8$ \\
Urea (mg/dl) & $29.35 \pm 8.49$ & $35.82 \pm 12.46$ & $183.2 \pm 62.39$ \\
Creatinine (mg/dl) & $0.77 \pm 0.2$ & $1.03 \pm 0.32$ & $5.46 \pm 2.01$ \\
$\begin{array}{l}\text { ACR } \\
\quad \text { (mg.alb/g.creat) }\end{array}$ & $9.1 \pm 6.85$ & $32.4 \pm 19.84$ & $366.62 \pm 228.10$
\end{tabular}

- Results are expressed as mean \pm SD

- Comparisons are made between group II, DM patients \& group III, DN patients with group I, control.

- Activity is expressed as: $\mathrm{mg} / \mathrm{dl}$ for FBS, urea \& creatinine; \% for HBA1 c; mg alb/g creatinine for ACR

\section{Relative quantitative of miRNA29-a}

Data represented in Table (2) show increased in relative quantitative of miRNA29-a in group III, DN (51.97 \pm 61.78$)$ and group II, DM (7.06 \pm $6.83)$ when compared with group I, control subjects $(0.8 \pm 0.2)$. Also Data represented in Figs. (1 A \& 1B) show a positive significant correlation between miRNA29-a (RQ) and (ACR \& HBA1C), this explains to us the covariant relationship between them.

Table (2): Levels of relative quantitative (RQ) for miR29-a in different studied groups.

\begin{tabular}{lccc}
\hline $\begin{array}{l}\text { Analytical } \\
\text { parameters }\end{array}$ & $\begin{array}{c}\text { Group I } \\
\mathrm{N}=20\end{array}$ & $\begin{array}{c}\text { Group II } \\
\mathrm{N}=50\end{array}$ & $\begin{array}{c}\text { Group III } \\
\mathrm{N}=50\end{array}$ \\
\hline miR-29a (RQ) & $0.8 \pm 0.2$ & $7.06 \pm 6.83$ & $51.97 \pm 61.78$ \\
\hline - Results are expressed as mean \pm SD. \\
- Comparisons are made between group II, DM patients \& group III, \\
DN patients with group I, control subjects.
\end{tabular}

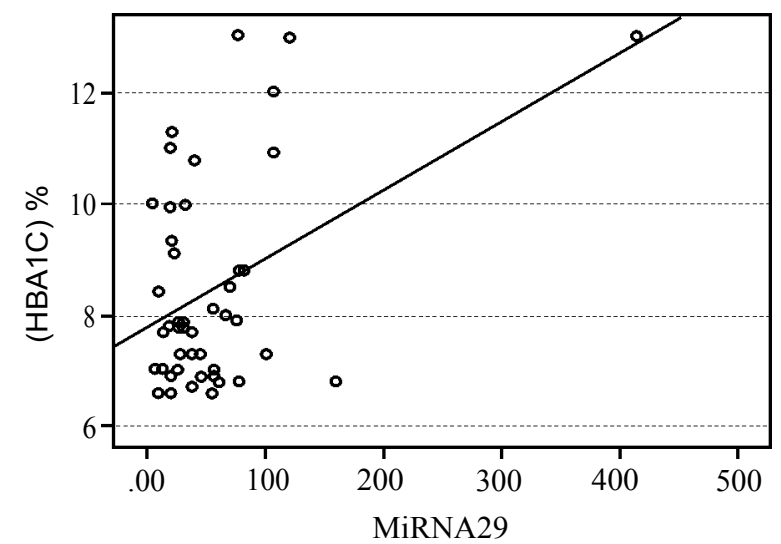

Fig. (1A): Correlation between HBA1c and miR29-a in diabetic nephropathy patient

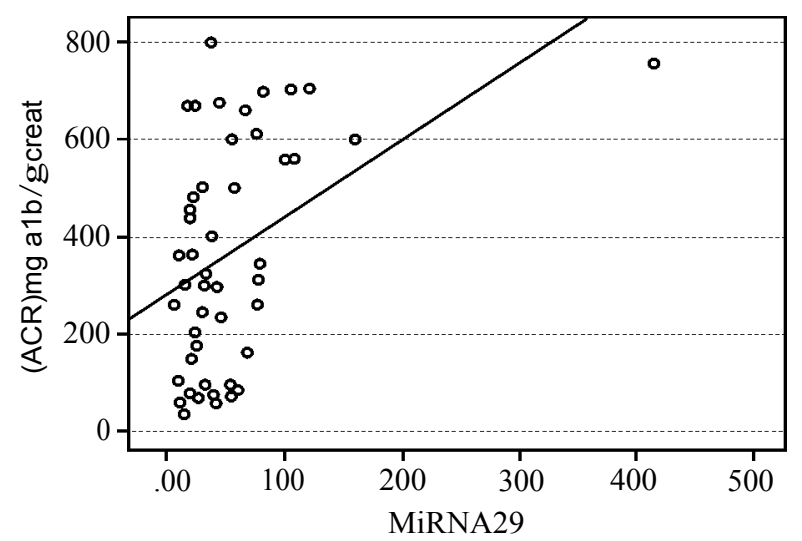

Fig. (1B): Correlation between ACR and miR29-a in diabetic nephropathy patients.

Feg. (1): Correlation of serum miR29a levels in patients with diabetic nephropathy. Pearson's correlation coefficient analysis was performed and $p<0.05$ is considered as significant difference. The result showed that the subjects with greater level of serum miR-29a exhibited more rapid ACR \& HBA1c changes in contrast to those with lower miR29a levels. The $\mathrm{X}$-axis represented changing rates of ACR \& HBA1c, the Y-axis referred to the relative quantitative of miRNA29-a level (versus Hs-SNORD68-11). 


\section{Discussion}

DN causes significant diseases and even deaths in patients with diabetes. Although the detection of protein in urine samples is considered the best standard to detect one of the first and reversible $\mathrm{DN}$, the sensitivity to diagnosing the exact disease, is dissatisfied [27]. There are many other signs that demonstrate performance in DN analysis or authentication those at risk of development. However, some of these tags cannot be truly special DN and may indicate other types of kidney disease, such as transport and primary glomerulonephritis [28] The need for highly stable and varied labeling DN and in advance DN individuals are required. The miRNA is well prepared to meet this need. The miRNA is very constant at room temperature [29].

A recent finding demonstrated that hyperglycemia-induced podocyte dysfunction was ameliorated by miRNA29-a promotion of nephrin acetylation [30]. According to this moment study, a recent study suggesting a series of urinary miRNAs that had not been previously associated kidney disease in patients with T1DM with different levels of albuminurium/DN. Among these miRNAs related to DN, miRNA29 is produced in different ways between patients who developed to DN after a long time in relation to non-patient patients [31]. An increase in the expression of many miRNAs has been observed in diabetes mellitus GK rats model, as increased expression of the myRNA-29 family in muscles, fat and liver, associated with insulin resistance [32]. According to this study is a recent study showed that an elevated level of miR-29a in urine, but not miR-29b and miR-29c, of T2DM patients with microalbuminuria and macroalbuminuria compared to those with normoalbuminuria [33].

On the contrary, Lv 2013 showed that urinary activities of miR-29 and miR-200 Family decreased in patients with chronic kidney disease, including certain anatomy DN, but the expression miR-29c closely followed the glomerular filtration rate and association not related to the extent of tubulointerstitial fibrosis [34].

\section{Conclusion}

The present data of this study implied that miRNA 29-a could serve as early indicator of DMmediated renal pathogenesis, which can be of importance in the aspect of preventive medicine.

\section{References}

1- NJOLSTAD P.R., SAGEN J.V., BJORKHAUG L., ODILI S., SHEHADEH N., BAKRY D., et al.: Permanent neonatal diabetes caused by glucokinase deficiency: Inborn error of the glucose-insulin signaling pathway. Diabetes Care, 52 (11): 2854-60, 2003.

2- GONZÁLEZ E.L., JOHANSSON S., WALLANDER M.A., and RODRÍGUEZ L.A.: Trends in the prevalence and incidence of diabetes in the UK: 1996-2005. J. Epidemiol. Community Health, 63: 332-6, 2009.

3- YANG W.C., HWANG S.J., CHIANG S.S., CHEN H.F., and TSAI S.T.: The impact of diabetes on economic costs in dialysis patients: Experiences in Taiwan. Diabetes research and clinical practice, 54 (Supple 1): S47-54, 2001.

4- BOYLE J.P., THOMPSON T.J., GREGG E.W., BARKER L.E., and WILLIAMSON D.F.: Projection of the year 2050 burden of diabetes in the US adult population: dynamic modeling of incidence, mortality, and prediabetes prevalence. Population Health Metrics, 8: 29, 2010.

5- DeFRONZO R.A. and FERRANNINI E.: Insulin resistance. A multifaceted syndrome responsible for NIDDM, obesity, hypertension, dyslipidemia, and atherosclerotic cardio vascular disease. Diabetes Care, 14: 173-94, 1991.

6- LAING S.P., SWERDLOW A.J., SLATER S.D., BURDEN A.C., MORRIS A., WAUGH N.R., et al.: Mortality from heart disease in a cohortof 23,000 patients with insulintreated diabetes. Diabetologia, 46: 760-65, 2003.

7- PATERSON A.D., RUTLEDGE B.N., CLEARY P.A., LACHIN J.M. and CROW R.S.: The effect of intensive diabetes treatment on resting heart rate in type 1 diabetes; the Diabetes Control and Complications Trial/Epidemiology of Diabetes Interventions and Complications study. Diabetes Care, 30: 2107-12, 2007.

8- LEHTO S., RONNEMAA T., PYORALA K. and LAAKSO M.: Predictors of stroke in middle-aged patients with non-insulin-dependent diabetes. Stroke, 27: 63-8, 1996.

9- FONG D.S., AIELLO L.P., FERRIS F.L., 3 rd KLEIN R.: Diabetic retinopathy. Diabetes Care, 27: 2540-53, 2004.

10- BOULTON A.J., VINIK A.I., AREZZO J.C., BRIL V., FELDMAN E.L., FREEMAN R., et al.: Diabetic neuropathies: A statement by the American Diabetes Association. Diabetes Care, 28: 956-62, 2005.

11- KALLURI R.: When epithelial cells decide to become mesenchymal-like cells. J. Clin. Invest., 119: 1417-19, 2009.

12-REIDY K., KANG H.M., HOSTETTER T. and SUSZTAK K.: Molecular mechanisms of diabetic kidney disease. The Journal of clinical investigation, 124: 2333-40, 2014

13- GROSS J.L., DE AZEVEDO M.J., SILVEIRO S.P., CANANI L.H., CARAMORI M.L. and ZELMANOVITZ T.: Diabetic nephropathy: Diagnosis, prevention, and treatment. Diabetes Care, 28: 164-176, 2005.

14- LEVEY A.S., BECKER C. and INKER L.A.: Glomerular filtration rate and albuminuria for detection and staging of acute and chronic kidney disease in adults: A systematic review. JAMA: The Journal of the American Medical Association, $313: 837-46,2015$. 
15- MENDELL J.T.: MicroRNAs: Critical regulators of development, cellular physiology and malignancy. Cell. Cycle., 4: 1179- 84, 2005.

16- GILAD S., MEIRI E., YOGEV Y., et al.: Serum microRNAs are promising novel biomarkers. PloS One., 3: e3 148, 2008.

17- BHATT K., MI Q.S. and DONG Z.: "MicroRNAs in kidneys: Biogenesis, regulation, and pathophysiological roles," American Journal of Physiology-Renal Physiology, 300 (3): F602-F10, 2011.

18- FERNANDEZ-VALVERDE S.L., TAFT R.J. and MATTICK J.S.: "MicroRNAs in [3-cell biology, insulin resistance, diabetes and its complications," Diabetes, 60 (7): 1825-31, 2011.

19- KATO M., ARCE L., WANG M., PUTTA S., LANTING L. and NATARAJAN R.: "A microRNA circuit mediates transforming growth factor- $\beta 1$ autoregulation in renal glomerular mesangial cells," Kidney International, 80 (4): 358-68, 2011.

20- ESQUELA-KERSCHER A. and SLACK F.J.: "OncomirsmicroRNAs with a role in cancer," Nature Reviews Cancer, 6 (4): 259-69, 2006.

21- JANSSEN H.L.A., REESINK H.W., LAWITZ E.J., et al.: "Treatment of HCV infection by targeting microRNA," The New England Journal of Medicine, 368: 1685-94, 2013.

22- LONG J., WANG Y., WANG W., CHANG B.H. and DANESH F.R.: MicroRNA-29c is a signature microRNA under high glucose conditions that targets Sprouty homolog 1 , and its in vivo knockdown prevents progression of diabetic nephropathy. The Journal of biological chemistry, 286: 11837-48, 2011.

23- WANG B., KOMERS R., CAREW R., WINBANKS C.E., XU B., et al.: Suppression of microRNA-29 expression by TGF-beta1 promotes collagen expression and renal fibrosis. J. Am. Soc. Nephrol., 23: 252-65, 2012.

24- YOUNG D.S., et al.: Clin. Chem., 18: 10, 1972.

25- NATHAN D.M., et al.: New Eng. J. Med., 3 10: 341-6, 1984.

26- YOUNG D.S.: Effects of disease on clinical lab. Tests, $4^{\text {th }}$ ed AACC, 2001.

27- TRIONFINI P., BENIGNI A. and REMUZZI G.: MicroRNAs in kidney physiology and disease. Nature Reviews Nephrology, 11: 23-33, 2015.

28- WANG C., LI C., et al.: New urinary biomarkers for diabetic kidney disease. Biomark. Res., 1 (1): 1-4, 2013.

29- MALL C., ROCKE D.M., et al.: Stability of miRNA in human urine supports its biomarker potential. Biomark Med., 7 (4): 623-3 1, 2013.

30- LIN C.L., LEE P.H. and HSU Y.C.: "MicroRNA-29a promotion of nephrin acetylation ameliorates hyperglycemia induced podocyte dysfunction," Journal of the American Society of Nephrology, 25 (8): 1698-709, 2014.

31- ARGYROPOULOS C., WANG K., McCLARTY S., et al.: Urinary microRNA profiling in the nephropathy of type 1 diabetes. PloS One, 8: e54662, 2013.

32- KANTHARIDIS P., WANG B., CAREW R.M. and LAN H.Y.: Diabetes Complications: The MicroRNA Perspective Diabetes, 60: 1832-7, 2011.

33- PENG H., ZHONG M., ZHAO W., et al.: Urinary miR29 correlates with albuminuria and carotid intima-media thickness in type 2 diabetes patients. PloS One, 8: e82607, 2013.

34- LV L.L., CAO Y.H., NI H.F., et al.: MicroRNA-29c in urinary exosome/microvesicle as a biomarker of renal fibrosis. American journal of physiology renal physiology, 305: 1220-27, 2013.

\title{
(microRNA-29) بإعتلال الكلى فى مرضى السكر (النوع الثانى)
}

\begin{abstract}
يعتبر إعتلال الكلى السكرى هو السبب الرئيسى الفشل الكلهى. وقد أوضحت الدراسات الديثة (miRNAs) يمكن أن ينتفع بها كدلائل

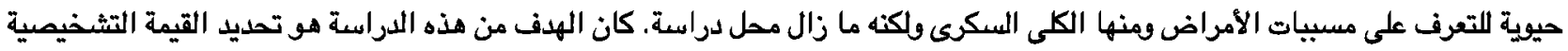

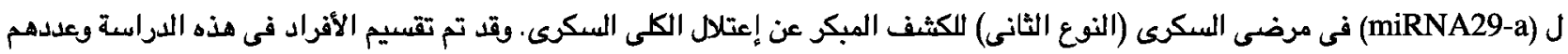

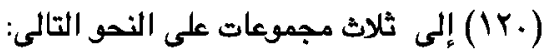

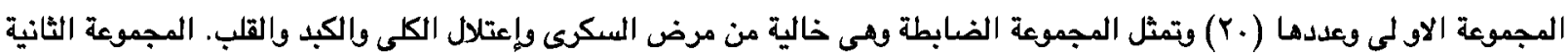

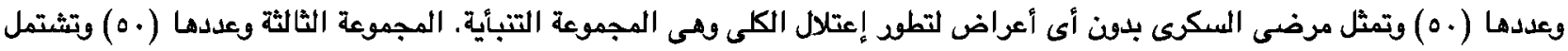

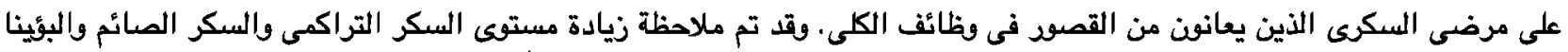

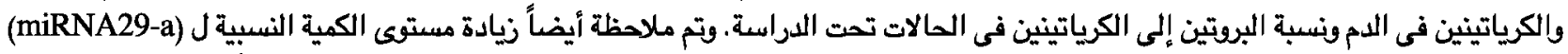

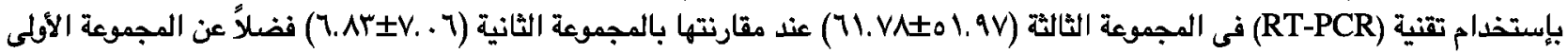

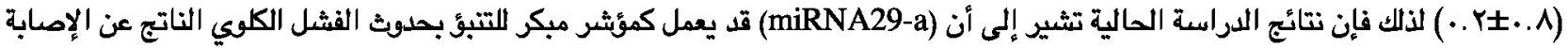

